\title{
Los reglamentos de agua: el caso de Cerrillos a fines del siglo XIX (provincia de Salta-Argentina)
}

\author{
The regulations of water: the case of Cerrillos at the end of the nineteenth \\ century (province of Salta-Argentina)
}

\author{
Daniel Medardo Ontivero \\ cerrilloscultura@gmail.com \\ Universidad Nacional de Salta
}

Fecha de recepción: 24 de julio de 2018

Fecha de aprobación: 21 de septiembre de 2018

\begin{abstract}
Resumen
Esta investigación estudia a los Reglamentos de Aguas surgidos en Cerrillos (Provincia de Salta- Argentina) en la segunda mitad del siglo XIX. El objetivo es establecer la naturaleza prescriptiva de los mismos y avanzar con el conocimiento respecto a los cambios dados, a partir de ese momento, en la gestión y administración del agua para riego en un espacio estratégico para el circuito ganadero orientado al norte chileno. El estudio se basa en información de carácter cualitativa que proviene de la Ordenanza que dio forma al Sindicato de Aguas (creado el 31 de julio de 1886) y al Reglamento de Aguas creado por este un año más tarde, lo cual nos permite aportar al conocimiento de los cambios y permanencias dados, en Hispanoamérica, respecto del manejo del agua para riego a fines del siglo XIX. En este sentido, tanto la discusión teórica como las implicaciones pragmáticas relativas a la organización social alrededor del sistema de riego, son aspectos que, si bien fueron tratados a nivel hispanoamericano -particularmente por contribuciones mexicanas- todavía no han sido tratados en el ámbito de la historiografía regional. De allí, el aporte de la investigación.
\end{abstract}

Palabras claves: Riego, Reglamentos de Aguas, Sindicato de Aguas, Institucionalización del agua, procesos modernizadores. 


\begin{abstract}
This research studies the Waters Regulations emerged in Cerrillos (Province of Salta - Argentina) in the second half of the 19th century. The objective is to establish the prescriptive nature of the same and to advance with knowledge about the changes given, from that moment, on the management and administration of water for irrigation in a strategic space for the livestock circuit oriented to the Chilean north. The study is based on qualitative information that comes from the Ordinance that gave shape to the Water Union (created on July 31, 1886) and the Water Regulations created by it a year later, which allows us to contribute to knowledge of the changes and permanences given, in Hispano-America, regarding the management of water for irrigation at the end of the 19th century. In this sense, both the theoretical discussion and the pragmatic implications related to social organization around the irrigation system are aspects that, although they were treated at a Spanish-American level -particularly by Mexicans- have not yet been addressed in the field of regional historiography. From there, the contribution of the investigation.
\end{abstract}

Keywords: Irrigation, Water Regulations, Water Syndicate, Water Institutionalization, modernizing processes. 


\section{Introducción ${ }^{1}$}

En Hispanoamérica, los Reglamentos de Agua y la intervención del Estado en la distribución de la misma, a través de organizaciones de regantes (Juntas de Aguas, Sindicatos, Asociación de Regantes, etc.), forman parte de un fenómeno propio de finales del siglo XIX y principios del XX. De esa manera, motivados por las transformaciones del Capitalismo Agrario, surgieron, en cada sistema de riego, asociaciones bajo estatutos y disciplinas que se encargaron de llevar a cabo procesos de centralización con el objetivo de ordenar la distribución de las aguas, garantizando que los beneficiarios -regantespudieran recibir de manera equitativa, en tiempo y en forma, las cuotas de aguas que les correspondiesen y la conservación de la infraestructura de regadío ${ }^{2}$. En este sentido, Palerm Viqueira ${ }^{3}$ señala una vinculación directa entre la reglamentación y la conformación de una organización de regantes, debido a que, esta última, sería la responsable de implementar la reglamentación. Respecto a esta vinculación, hay que decir que, no estaría ajena de los conflictos, dado que el agua no solo se convirtió en un recurso económico, factor clave para el desarrollo agrario de los estados en construcción, sino que, también, en un recurso político. Esta distinción resulta destacable en la medida en que el control del agua implicó un ejercicio del poder y el dominio de un campo político, donde participaron diferentes actores interesados en la apropiación y gestión del agua ${ }^{4}$.

En el caso de nuestra área de estudio, el análisis de los Reglamentos de Aguas y las organizaciones por mandato del estado en el actual territorio argentino, como son los Sindicatos de Aguas, está por realizarse, dado que, de acuerdo con Omar Miranda ${ }^{5}$, tradicionalmente la historiografía argentina estuvo abocada al estudio de la agricultura de la Pampa Húmeda. Como resultado de ello, el factor de producción, en donde se centraron los estudios, fue la "tierra". Para el autor, esto fue motivo de un cierto desinterés por reflexiones acerca del agua para riego en el conjunto de las relaciones sociales de la agricultura en la Argentina.

Los Reglamentos de Agua que surgen en el Departamento de Cerrillos ${ }^{6}$ a fines

$1 \quad$ Una primera versión de este texto se la puede encontrar en: Daniel Medardo Ontivero, "Riego, Poder y Estado municipal en San José de los Cerrillos (Salta 1857-1920): entre tensiones, conflictos y procesos de modernización". Tesis doctoral (inédita). Tucumán: Universidad Nacional de Tucumán (UNT); Facultad de Filosofía y Letras, 2018.

2 Jacinta Palerm V. y Tomás Martínez S. eds. "El espíritu colectivo en los sistemas de riego," en: Aventura con el agua. La administración del agua de riego: Historia y Teoría (México: Colegio de Postgraduados, Sede Montecillo en Texcoco, 2009), 364.

3 Jacinta Palerm, "Las Juntas de Agua y las Unidades de Riego", en: Aventura con el agua. La administración del agua de riego: Historia y Teoría (México: Colegio de Postgraduados, Sede Montecillo en Texcoco, 2009), 196.

$4 \quad$ Patricia Ávila García, "Cambio global y recursos hídricos en México: hidropolítica y conflictos contemporáneos por el agua".

5 Omar Miranda, "Trayectoria tecnológica y uso del agua en la Agricultura argentina bajo riego," Revista Agricultura, Sociedad y Desarrollo 6.5, (2009).

6 El Departamento de Cerrillos es uno de los 23 departamentos en los que se divide la provincia de 
del siglo XIX, se elaboraron debido a una complejidad creciente motivada por el interés del Estado nacional argentino por el fomento de la agricultura y, en el caso de nuestra área, por los procesos económicos que llevaron a una reorientación de la economía hacia el mercado salitrero del Norte de Chile ${ }^{7}$. Dado que hubo un incremento de la frontera agraria, producto de la demanda de forrajeras -maíz y alfalfa- para cubrir la demanda del circuito ganadero orientado al país trasandino, es que apareció el "Problema de la Irrigación", hecho que se plantea no sólo como un problema técnico a resolver, sino como un problema social, de cultura y de dominación ${ }^{8}$ relacionado con el accionar de distintos actores (dueños de las fincas), quienes al detentar el poder pretendieron el control del agua. La detentación del mismo se hizo mediante diferentes instancias de participación, ya fuera a través del Concejo Municipal -institución de carácter local con atributos legislativos- o de los Sindicatos de Agua departamentales (Cerrillos y Rosario de Lerma ${ }^{9}$ ) -órganos a cargos de regantes- y principalmente, a través de una legislación específica creada desde finales de la década del ' 80 con el propósito de reglamentar el uso del agua para riego. Como es de suponer, esta situación favoreció solo a un sector de la sociedad local, que fue aquel que concentró entre sus manos la tierra y el agua, a través de diferentes estrategias económicas y políticas.

Salta (Argentina). El Municipio de Cerrillos, uno de los que compone el departamento actualmente, es el más pequeño de la provincia en extensión territorial, con $224 \mathrm{~km}^{2}$, y está situado en el centro del Valle de Lerma, por lo que es denominado el corazón geográfico de la zona. Esta ubicación lo ha convertido en un punto estratégico dentro de la provincia de Salta, dado que es un paso obligado entre el Valle de Lerma y los Valles Calchaquíes. Limita al norte y al este con el Departamento Capital, al sur con Chicoana y al oeste con Rosario de Lerma.

$7 \quad$ A efectos de ampliar este tema se sugiere la lectura de: Daniel Medardo Ontivero, "Efectos del desarrollo salitrero en el noroeste argentino. El caso de San José de los Cerrillos a fines del siglo XIX", Revista Notas Históricas y Geográficas 20 (2018): 88-121. En dicho artículo se examina los efectos económicos producidos por el desarrollo salitrero de Tarapacá a fines del siglo XIX a partir del estudio de los procesos de transformación de la producción agropecuaria y el sistema de regadío en el Departamento de Cerrillos (Provincia de SaltaNorte de Argentina). Con tal propósito, se hace énfasis no sólo en las características de la producción agraria a fines del siglo XIX, sino, en las transformaciones económicas que motivaron el incremento de la frontera agraria con la consecuente manifestación de una serie de conflictos en torno a la distribución del agua de riego. En la investigación queda demostrado que la demanda de ganado vacuno por parte de la región salitrera fue la promotora de una reorientación económica producida en los Valles de Lerma y Calchaquí, que comenzaron a desarrollarse en función de la demanda ganadera, pero, con efectos significativos en el agro y en la demanda de agua para regadío. Por tal razón, la investigación adquiere relevancia dado que permite comprender que ante los procesos de la "atlantización" por el desarrollo del mercado agroexportador de las economías regionales del norte argentino, existieron áreas que fueron influidas económicamente por otras regiones, como la del Tarapacá.

8 Palerm Viqueira, Jacinta y Martínez Saldaña Tomás, Antropología del Agua. Mimeo. (s/f): 5.

9 El municipio de Rosario de Lerma es cabecera del departamento homónimo, y se encuentra a $33 \mathrm{~km}$ de la Ciudad de Salta. El Problema de la Irrigación se genera debido a que de allí se captaba el agua que se distribuía a través de un sistema de acequias (que eran canales de diversas dimensiones que servían para el traslado del agua a los campos de cultivo) por las fincas del municipio de Cerrillos. Dado que las aguas tenían su origen en el río de la Quebrada del Toro, ubicado en el actual Departamento de Rosario de Lerma y en la parte más elevada del espacio hidráulico compuesto por ambos departamentos (Cerrillos y Rosario de Lerma), los conflictos fueron productos de la creación de la escasez del agua. 


\section{Antecedentes sobre el manejo del agua: el caso del Reglamento de Irrigación del Departamento de Campo Santo (Provincia de Salta- Norte argentino)}

Con la abolición del Cabildo en 1825, el joven estado provincial salteño se vio en la necesidad de tomar las riendas sobre el asunto de las aguas, aunque siempre respetando las prerrogativas y facultades de orden local. De esa manera, desde el Poder Ejecutivo si bien se aplicaron algunas medidas que podríamos suponer encuadradas en políticas hídricas de largo alcance, no hemos encontrado evidencias de acciones concretas que afectaran a todo el territorio provincial salteño, quizás debido a que tampoco existieron políticas relacionadas con el desarrollo capitalista agrario que serán propias de la segunda mitad del XIX. Es así que, en un contexto político en donde el estado provincial todavía era incipiente, se realizaron una serie de acciones alrededor del control de las aguas de riego generalmente de interés para la élite terrateniente. Estas fueron las siguientes: a) conformación de un Reglamento de Aguas (1839) desde donde se establecerían disposiciones sobre los Jueces de Aguas y la creación de una Comisión para controlarlos; b) emisión de un Decreto sobre las aguas del río Calchaquí (1841) a los efectos de normativizar la distribución del agua en tiempo de escasez; y c), elaboración de un Decreto por parte del gobernador Don Manuel Antonio Saravia referido a cortar las disputas que había por el agua que "[...] descendían por acequias del poniente de esta ciudad" 10 .

Décadas posteriores, ya bajo otro contexto político regulado por la Constitución Nacional argentina de 1853 y por la Ley Orgánica de Municipalidades (promulgada hacia 1856), la situación se planteará de manera distinta en lo referido al manejo del agua. Desde ese momento, tanto en el orden nacional como en el provincial, se comenzaron a vislumbrar legislaciones -Código Civil, Ley de Municipalidades, Constituciones nacional y provinciales, Códigos Rurales, etc.- consideradas de carácter moderno, que repercutirán en los ámbitos locales, como los municipios. A partir de allí, un proceso de municipalización de los territorios llevó a que los poderes locales, organizados a través de redes familiares y dueña de las tierras y acequias, se hicieran cargo de una serie de atribuciones en la toma de decisiones como por ejemplo, aquellas referidas a la gestión y a la distribución del agua para riego.

Desde el Poder Ejecutivo provincial también hubo intentos de armonizar el carácter municipal de la legislación de aguas. Tal sería el caso del Reglamento de Irrigación del Departamento de Campo Santo, nacido por impulso del Concejo Municipal local en el año 1867. Este fue impuesto por fuerza de Ley a toda la provincia de Salta y sirvió, como referencia, para otros reglamentos locales hasta 1884, momento en el

10 Atilio Cornejo, Contribución a la Historia del Derecho de Aguas de Salta (Salta: Publicación del Instituto de San Felipe y Santiago de Estudios Históricos de Salta, 1980), 84. 
que se elaboró el Código Rural para la provincia ${ }^{11}$. A pesar de esta acción política, el proceso de institucionalización del manejo del agua a nivel provincial tuvo que sortear el entramado de poderes a nivel local, basados en el uso de costumbres y derechos adquiridos, situación que se contrapuso a la idea del agua como recurso público.

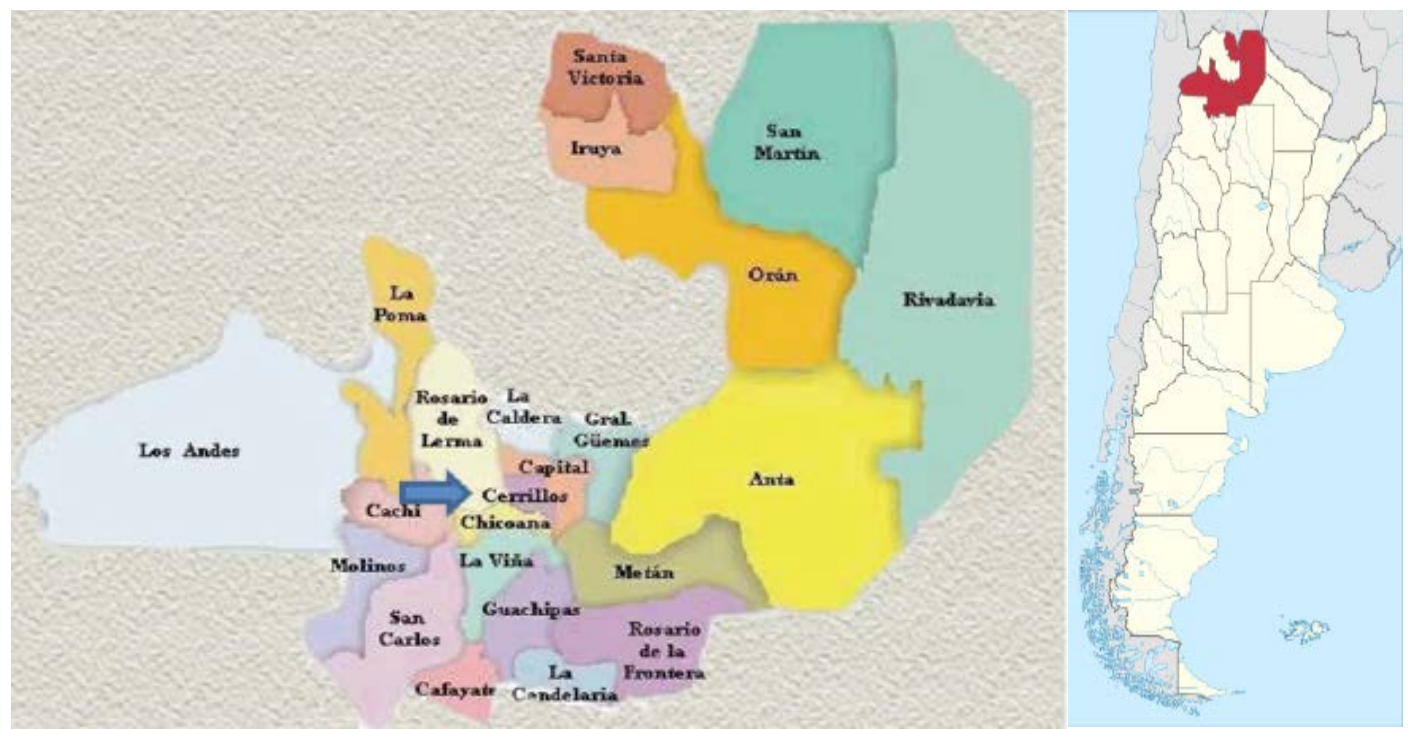

Mapa 1. Ubicación del Departamento de Cerrillos (Provincia de Salta)

Fuente: Salta, División política en http://www.portaldesalta.gov.ar/deparsalta.htm

El Reglamento de Campo Santo (ver Mapa 1) ${ }^{12}$ surgió como fruto de tres objetivos: el primero de ellos, cumplir con las atribuciones concedidas a los municipios por la Ley de Municipalidades en lo referido a la reglamentación del uso del agua; el segundo, regular la distribución del agua en situación de escasez de la misma, garantizando el acceso de un recurso importante para el desarrollo de la agricultura; el tercero, favorecer a los intereses económicos de aquellos que eran propietarios e integrantes del Concejo Municipal a la vez. De esa manera, se trató de beneficiar a las familias que eran propietarias de las tierras destinadas al azúcar, como lo era el caso de la familia Fernández Cornejo. Sobre esta última, es oportuno señalar el vínculo que existió entre los propósitos de la citada Ordenanza y el poder político, dado que Don Juan Fernández Cornejo ${ }^{13}$, uno de los beneficiarios, fue el presidente del Concejo Municipal.

11 Federico Villareal y Mabel Manzanal, "Descentralización y poder en la administración del agua de riego. El caso de la cuenca del río Calchaquí en el departamento de San Carlos, Salta, Argentina", Campo Territorio: Revista de geografia agraria, 12.6 (2011): 32-62.

12 Campo Santo es una localidad en el departamento General Güemes (Provincia de Salta). Se encuentra a $50 \mathrm{~km}$ de la ciudad de Salta, capital de la provincia, en el NOA (Noroeste de Argentina).

13 Don Juan Fernández Cornejo fue hijo del Coronel Mayor Don José Antonino Fernández Cornejo y de la Corte y de Don Josefa de Usandivaras y Figueroa y nieto del coronel Don Juan Adrián Cornejo y Rendón y 
El Reglamento en cuestión se dividía en 17 artículos, señalándose en el primero, las porciones de agua en la que se distribuía el río Siancas. En los próximos articulados, se regulaba sobre la distribución y la administración de las aguas, la que estaría a cargo de una Comisión distribuidora. Se hablaba también de un vigilante, quien cumpliría su función de acuerdo a la disponibilidad de agua, estando supeditado tanto al control municipal como al cumplimiento de multas por el incumplimiento de sus funciones. Respecto a la división de las acequias, el reglamento establecía que los propietarios tendrían que señalar sus canales, al menos en sus bocas tomas con marcos de cal y piedras. Los mismos serían costeados, nos dice uno de sus artículos, por el propietario interesado. Se estipulaba también sobre las obligaciones de los propietarios respecto a la conservación de la infraestructura hidráulica.

En el reglamento, se hacía énfasis en el rol del municipio sobre el control de las acequias, así como en los puentes o pasos por donde estas pasaban con miras a garantizar el tránsito. También eran tratados los derrames de las aguas en los caminos, los respectivos reparos y las multas como mecanismos de sanción de tipo económico.

De acuerdo a lo observado, el reglamento aseguraba el cumplimiento de los derechos de extracción de los usuarios con derechos adquiridos. De este ejemplo, queda en evidencia la importancia que se daba en Salta al problema del agua -seguramente fruto de las transformaciones agrarias-; no solo en lo referido a los conceptos doctrinarios respecto al dominio del agua, sino a la legislación manifestada a través de los reglamentos de agua. En este sentido, es propicio pensar sobre la importancia que se le daba al agua no solo en términos de recurso económico, sino como un recurso político a partir del cual se confirmaban los privilegios logrados por los grandes propietarios. En Salta, de acuerdo a Diego Ashur Mas ${ }^{14}$, el manejo del agua en la segunda mitad del siglo XIX estuvo en manos de los grandes propietarios, quienes la administraban a través de los municipios. Esta circunstancia provocó que los intentos de centralización del manejo del agua se vieran retardados y se tornaran conflictivos en la medida que afectaron a los intereses de los grandes propietarios.

\section{Del Sindicato de Aguas del Departamento de Cerrillos (1886)}

Teniendo en cuenta las características del sistema de riego en Cerrillos en el siglo XIX, pueden identificarse dos lógicas organizativas referidas al mismo. La primera, que se extiende desde el período colonial hasta entrada la segunda mitad del siglo

Doña Clara de la Corte y Rosas. La participación de Don Juan Fernández Cornejo no se limitó al ámbito local, haciéndolo a nivel provincial como Senador.

14 Diego Ashur Mas, "Salta: La institucionalización del agua", en: Eduardo La crisis del agua en Salta. Entre la sequía y la inundación, Terry Hoops y Ashur, (Salta: Center for latin American and Caribean StudiesUniversidad Estatal de Michigan- Fundación CAPACITAR, 2004), 151. 
XIX, se caracterizó por la administración del agua por parte de los propios regantes (familias propietarias), quienes realizaban, de manera autogestionada, las tareas de mantenimiento y operación del sistema. Se hacía con base en las costumbres y se regía dentro de una jurisprudencia colonial basada en la sesión de derechos a través de las mercedes de agua o compra o herencias ${ }^{15}$. Ya en la segunda mitad del siglo XIX, esta característica sirvió a los efectos de sentar precedente legal sobre los derechos adquiridos frente a la presión de la centralización estatal. Dado que el sistema de riego era pequeño no se requirió de una burocracia especializada del agua. Es así que, desde el punto de vista técnico, el manejo y la distribución del agua fue relativamente sencillo y estuvo supeditado a un mantenimiento frecuente por parte de los propios regantes, quienes aportaban el recurso económico y humano (peones). En este tipo de organización social del uso hídrico, tampoco se requirió de la elaboración de reglamentos, por lo que, el manejo del agua se hizo en base al conocimiento empírico tradicional y sostenido, a través del tiempo, en base a los acuerdos y convenios, verbales o protocolarizados, surgidos entre los dueños de las acequias.

La segunda instancia organizativa, en cambio, comenzará a perfilarse desde 1880 en adelante, en el marco de los procesos de centralización administrativa llevadas a cabo por el Concejo Municipal, y de las transformaciones económicas provocadas por el incremento de la frontera agraria en virtud del desarrollo de un circuito ganadero que demandaba forrajes (por ejemplo, alfalfa) ${ }^{16}$.

Por lo que se infiere, fue gradual el proceso que llevó a que se configurara una nueva lógica administrativa del agua. Si bien esta estuvo regulada desde el propio estado local en formación, fue supeditada a los intereses corporativos de los propietarios de las tierras a través del Sindicato del Agua. De esta manera, la administración del agua para riego pasó a ser injerencia de un aparato centralizador y de un personal administrativo especializado, así como también quedó en manos de un órgano corporativo como el Sindicato de Aguas que, en otros casos como el mexicano, recibe el nombre de Juntas de Aguas $^{17}$.

Ante el crecimiento del espacio hidráulico, resultado de la reorientación productiva hacia la ganadería, desde el Concejo Municipal se generaron acciones legislativas tendientes a perfilar una gestión del agua distinta a la planteada en ese momento. La

15 Cornejo, Contribución a la Historia del Derecho de Aguas de Salta..., 80.

16 Michel y Savic, señalan que tanto la "atlantización" de la economía hacia la región pampeana, como la inflexión económica que significará la Guerra del Pacífico y desarrollo de la industria del nitrato en el Norte de Chile, los valles de Lerma y Calchaquí fueron reorientando su economía hacia la ganadería vacuna y la producción de forrajeras. De acuerdo a estas autoras, para el año 1910, la superficie sembrada en los valles de Lerma y Calchaquí significaba un $94 \%$ del total provincial. Azucena del Valle Michel, y Elizabeth Savic, "Comerciantes-ganaderos y propietarios. Salta (1880-1920)," Cuadernos de Humanidades 11 (1999): 186.

17 Palerm, "Las Juntas de Agua y las Unidades de Riego", 196; Enrique Palacios Vélez, "Sobre las Juntas de Aguas", en: Aventura con el agua. La administración del agua de riego: Historia y Teoría, Jacinta Palerm V. y Tomás Martínez S., eds. (México: Colegio de Postgraduados, Sede Montecillo en Texcoco, 2009), 217-225. 
misma, en la que tendría intervención directa el Concejo Municipal bajo influencia del gobierno provincial y legislaciones a nivel nacional ${ }^{18}$, sería llevada a cabo por una burocracia especializada que impulsaría acciones tendientes al mantenimiento de la infraestructura de regadío y de la búsqueda de financiamiento (a través del cobro de un canon de riego) para el pago del personal a cargo de la distribución del agua ${ }^{19}$. Junto con ello, además, se llevó a cabo la creación de instrumentos legales que consistían en Reglamentos de Aguas que permitieron un ordenamiento de las aguas e inclusive, la sanción económica a aquellos que no pagaran las cuotas por el acceso al riego, o a los que incurrieran en infracciones tales como el robo del agua.

La conformación del Sindicato de Aguas departamental, y, más tarde, el Sindicato Central Mixto de regantes de los Departamentos de Cerrillos y Rosario de Lerma, fue el resultado del avance de los procesos de institucionalización dados a nivel nacional (a través del Código Civil) y provincial (Código Rural 1881; 1884), pero, principalmente, de un largo proceso de discusiones y acuerdos producto del denominado Problema de la Irrigación surgido entre el '60 y ' $70^{20}$. De esta manera, la creación del Sindicato de Aguas (31 de julio de 1886) si bien fue impulsada desde el órgano político local, también fue el resultado de sugerencias y demandas de los vecinos propietarios de tierras y de las acequias. Este sirvió, aunque a nivel embrionario, a los efectos de una centralización de la gestión del agua y de una administración eficaz -a través de la creación de una legislación y de un cuerpo de funcionarios- del recurso hídrico.

La tarea encarada no fue fácil, debido a que la conformación del Sindicato de Agua presentaba un problema a resolver: la falta de reconocimiento por parte de algunos regantes a los nuevos esquemas de gestión/administración del agua. La principal razón respondía al hecho de que los regantes no encontraban legitimidad jurídica en

18 De esta manera, debido el avance de los procesos de institucionalización dados a nivel nacional (a través del Código Civil) y provincial (Código Rural 1881; 1884), el Concejo Municipal se vio obligado a la creación del Sindicato de Aguas el 31 de julio de 1886. La creación de esta corporación no es un fenómeno sui generis, sino que respondió a un fenómeno hispanoamericano que significó la creación de Corporaciones del Agua, tales como Juntas de Agua o Unidades de Riego; como así también, Leyes o Reglamentos de Agua que sirvieron a los efectos de regular la distribución equitativa del agua frente a un crecimiento de su demanda por el desarrollo de un Capitalismo Agrario. Ver: Jacinta Palerm Viqueira y Tomás Martínez S., Eds., Aventuras con el Agua. La Administración del agua de riego: Historia y Teoría (México: Colegio de Post- grado, Sede Montecillo en Texcoco, 2009).

19 La organización social del agua, según Palerm Viqueira, no tiene expresión material directa, sino que se la observa a través de distintas actividades tales como: mantenimiento de las bocas tomas, de las acequias y de canales de regadío, quién da la orden, quiénes van, quiénes sancionan a los que no van, quién o quiénes llevan un registro. Es decir, la organización social del agua se trata de la capacidad de movilizar el recurso humano y material a los efectos del mantenimiento de la infraestructura de regadío. Palerm Viqueira y Martínez S. Aventuras con el Agua, 187.

20 Se denomina Problema de Irrigación a los conflictos generados por la equitativa distribución del agua entre los usuarios de la parte de Arriba (Departamento de Rosario de Lerma) y los usuarios de la parte de Abajo (Departamento de Cerrillos) planteados en la década del '60. El caso tuvo resonancia dado que se lo judicializó resolviéndose a favor de los propietarios de las bocas tomas de Cerrillos y denegándose la apertura de nuevas boca tomas solicitadas por los vecinos de Rosario de Lerma. 
ellos. Esto se debía a que ese nuevo orden, aplicado a través de instancias organizativas y reglamentarias de procedencia estatal, alteraban las reglas de juego respecto del uso del agua que había sido llevado a cabo, hasta ese momento, por las familias propietarias de tierras y acequias. Algunos regantes consideraban que el acceso a la misma era por derecho adquirido, lo cual invalidaba al estado local a cualquier intervención. Ello explica, tal cual lo señalara Ashur ${ }^{21}$, por qué los reglamentos de aguas tardaron años en perfeccionarse e incorporarse a la práctica cotidiana y por qué muchos vecinos hicieron uso de prácticas sociales (hurto) que provocaron la escasez del agua en los distritos de riego, sin importarles mucho el cumplimiento de las reglamentaciones, tal cual lo indica Gómez Serrano para el caso de Aguascalientes (México) $^{22}$. En consecuencia, la aparición de las primeras reglamentaciones sobre el agua en Cerrillos respondió, además de la jurisprudencia emanada desde el Estado nacional y provincial, a la necesidad de diversos sectores sociales de contar con una normatividad que permitiera regular el acceso al agua, su control y su uso, en un contexto en que la población y las actividades agrícolas estuvieron en pleno crecimiento. En ese ámbito de cambios, la naturaleza de la distribución del agua estuvo asentada en la inequidad, dado que el dominio del agua se concentró en unos pocos propietarios de acequias o poseedores de tierras. Por ende, se generó una situación en la que el conjunto de potenciales usuarios tuvo que generar las condiciones jurídicas para acceder al agua.

\section{Del Reglamento de Aguas}

El Sindicato tuvo diversas atribuciones, las cuales quedaban expresadas en un Reglamento de Aguas. Entre ellas se destacaba la repartición de las aguas públicas en sus bocas tomas sobre el río de la Quebrada del Toro ${ }^{23}$, siguiendo las costumbres y los títulos de propiedad. Junto a esta, se determinaba el día y el turno (tandas) del repartimiento de las aguas, así como las multas que se debían de aplicar a todo aquel que hiciera caso omiso de las normas. Tales medidas significaban un cambio en las prác-

21 Eduardo Ashur, "Introducción”, en: La crisis del agua en Salta. Entre la sequía y la inundación, Terry Hoops y Eduardo Ashur (Salta: Center for latin American and Caribean Studies- Universidad Estatal de Michigan- Fundación CAPACITAR, 2004), 151.

22 Jesús Gómez Serrano, "La administración de agua en el tránsito del Antigua Régimen a la República. Aguascalientes, 1821-1835," Relaciones 136 (2013): 187-222.

23 La quebrada del Toro, es un accidente geográfico (quebrada) ubicado entre la localidad de Campo Quijano $(1521 \mathrm{~m})$ y Puerta Tastil, en el Departamento Rosario de Lerma, provincia de Salta. Forma parte del sistema de cañones de los Andes del noroeste argentino que descienden de la cara oriental de la Puna de Atacama desde alturas que superan los $5000 \mathrm{~m}$ sobre el nivel del mar hasta alcanzar los valles inferiores, en el caso de la del Toro, el sudoeste del valle de Lerma. Con unos $90 \mathrm{~km}$ de longitud desde los Altos de Muñano al oeste, con su mayor altura en Abra Blanca (4180 msnm), y Campo Quijano al este, el cañón del Toro tiene una orientación general noroeste-sudeste con una pendiente general de alrededor del $3 \%$, y está flanqueado por sierras que se elevan por encima de los $4000 \mathrm{msnm}$, llegando con el Nevado de Chañi a los $5896 \mathrm{~m} .2$ 
ticas de uso del agua que, como ya lo hemos ejemplificado, perjudicaban a algunos regantes en diferentes grados y situaciones. En lo referido a la distribución de agua, se planteaba la modalidad del tandeo ${ }^{24}$. Este consistía, como se advierte en el reglamento analizado y los que surgirán en el departamento a posteriori, en que cada usuario recibía un cierto número de horas de agua en un ciclo mensual en el período más crítico para el departamento, el que se extendía desde abril hasta el inicio de las lluvias, esto era noviembre/diciembre.

De acuerdo a lo observado, la cantidad de regantes que recibirían las tandas de agua era propia de cada distrito de riego. El sistema de tandeo dependía del agua que provenía de las acequias y de los derechos adquiridos por los propietarios. Además de estas características, desde el reglamento se observa que la distribución del agua se hacía teniendo en cuenta el tamaño de las propiedades y, si estas poseían o no, molinos hidráulicos.

Con lo señalado, lo que queda en evidencia es la existencia de un nuevo principio de dotación de agua en donde un regante debía recibir agua en proporción a la cantidad de la tierra que poseía o sobre la que tenía derechos. Sin embargo, como se verá, continuarán existiendo privilegios en ciertas dotaciones de agua, ya sea por razones políticas o por adquisición de derechos. Ello puede ser corroborado en el reglamento correspondiente a la acequia de Olmos y que fuera analizado junto al del Sindicato de Aguas: "[...] Terminado los tres días en otros Cerrillos pasará el agua durante cuatro a Olmos y su distribución será: Don Pedro Cánepa dos días y los dos días restantes entre los diversos propietarios..." 25

De acuerdo a otras evidencias, resulta oportuno pensar que otro factor que regulaba el tandeo tuvo que ver, seguramente, con las prácticas sociales, que, a pesar de las sanciones, eran llevadas a cabo por los funcionarios del agua, quienes desviaban la misma de acuerdo a sus preferencias y vinculaciones familiares. Cuando terminaba el período de tandeo, tal cual como se hace en la actualidad, se estipulaba un período de limpieza de las acequias ${ }^{26}$. De acuerdo al reglamento, dicha limpieza estaría a cargo de los mismos propietarios, quienes estaban obligados a enviar personal para las tareas respectivas. Así, en el reglamento de la acequia de Olmos (1890), regulada por el Sindicato departamental, se ordenaba lo siguiente:

24 Distribución del agua de riego alternativamente o por tandas acordado por días u horas.

25 AHMC, $A C M$, "Reglamento para la Distribución de turnos en la acequia de Olmos" 29 de junio de 1890.

26 La conservación de las bocas tomas, acequias, caminos, puentes, drenes, obras de defensa, etc. era una de las labores de carácter permanente en los distritos de riego. Según Antonio Rodríguez L., su importancia era capital, pues cuando se descuidaba la atención de las obras resultaban interrupciones en el servicio de riego de los usuarios, que les ocasionaba perjuicios económicos muchas veces de carácter grave. Antonio Rodríguez L., "El desarrollo y operación de los sistemas de riego en México," en: Aventuras con el Agua. La Administración del agua de riego, Palerm y Martínez S. (México: Colegio de Postgraduados, Sede Montecillo en Texcoco, 2009), 421. 
“[...] El 15 de Abril de cada año todos los interesados en contribuir con un peón, en proporción de 6 horas de uso del agua, para la limpieza general de la acequia que debe terminarse antes del $1^{\circ}$ de Mayo, día que empezará el turno[... $]^{\prime 27}$

En síntesis, el agua se distribuía en turnos fijados (tandas) de acuerdo a la época y el día; siendo su libre uso multado según la gravedad del caso y de los prejuicios que ocasionare. Sobre el desvío del agua, el Reglamento era claro al respecto:

“[...] A todo aquel que impidiere el libre uso de las aguas, bien sea desviando el curso de las ascequias, obstruyendo las boca- tomas, poniendo obstáculos o atajadizos a la corriente misma o el curso del Río, se le obligará a volver las tomas y acequias al estado en que antes se encontraron y a pagar una multa $[\ldots]^{\prime 28}$

En este sentido, se creaba un cuerpo de funcionarios (Juez de río, Comisario Repartidor, Secretario de Sindicato, Alguacil) que iban a ser los que ejercerían el control respectivo. Uno de esos funcionarios era, por ejemplo, el Comisario Repartidor cuya atribución se orientaba a determinar un registro de los regantes y a partir de este, la repartición el agua. También se establecían algunos derechos y obligaciones de los propietarios, quienes para recibir el agua debían acudir al acondicionamiento de las acequias. Si bien en algunos casos, se daba la ocasión en el que un propietario hiciese el trabajo sin la intervención de otro, tenía derecho a reclamar, dada la normativa vigente, la indemnización al Sindicato.

Recién, para 1887, se puso en vigencia un reglamento más específico, dado que se consideraba necesario crear los recursos económicos con los que el Sindicato iba a poder manejarse:

"[...] sosteniendo los empleados necesarios asi para la buena y regular atención y equitativa distribución de las aguas de irrigacion en el Departamento como para la buena marcha administrativa de la Corporación Sindical necesitandose para los primeros buenos Jueces de Aguas y Comisarios Repartidores en las acequias de turno y una ordenanza que corran con el mecanismo materias de la administración $[\ldots]^{29}$

El mencionado reglamento había sido conformado por el Sindicato de Aguas y estipulaba diversos aspectos, entre ellos, las tareas que debían realizar los Comisarios Repartidores. Esta situación resulta interesante dado que, era un signo de la creciente

27 AHMC, $A C M$, "Reglamento para la Distribución de turnos en la acequia de Olmos" 29 de junio de 1890.

28 AHMC, $A C M$, "Ordenanza de Reglamento para el Sindicato de aguas del Departamento de Cerrillos". Salta, 31 de julio de 1886.

29 AHMC, $A C M$, "Reglamento del Sindicato de Aguas del Departamento de Cerrillos" 18 de junio de 1887. 
modernización que atravesaban las diferentes instancias de administración de territorio municipal. Por primera vez, se dejaba de lado el rol del agente económico privado como responsable de la gestión, y se pasó a una administración del agua más ordenada y manejada por funcionarios que recibían honorarios por su tarea. Ello provocó la conformación de una estructura administrativa que, por razones obvias, requería de fuentes de financiamiento por lo que se procuró de los mecanismos de cobro y control a través de funcionarios designados para tal fin.

Otro funcionario que aparecía en la estructura burocrática era el Juez de Río, de quien también se determinó una serie de obligaciones, tales como mantener con criterio equitativo la cantidad de agua que debía corresponder por cada acequia, o la de conservar las tomas de agua ante los desbordes que se pudieran generar, entre otros. Con la ordenanza y las reglamentaciones, se fue logrando dar forma a una organización, el Sindicato del Agua, cuyo propósito era ordenar la accesibilidad al recurso hídrico y mayor control en su distribución, uno de los problemas a resolver más importante para el desarrollo agrario.

A nivel general, se advierte que el Comité Ejecutivo del Sindicato tuvo la responsabilidad del mantenimiento del sistema de riego y se constituyó en portador de las demandas y conflictos de los regantes, aunque jamás dejando de lado el rol que por legislación tenía el Concejo Municipal. Además, era atribución del Comité Ejecutivo (compuesto por el presidente, tesorero y secretario) establecer los derechos de los propietarios sobre los turnos de agua y examinar los títulos.

La organización del Sindicato Departamental de Aguas -entendido como un mecanismo integrador y cohesionador de los usuarios regantes- ha sido establecida desde el Código Rural de 1884. Antes de esto, el sistema de riego era manejado por las familias propietarias, quienes manifestaban uso del mismo fundamentado en las costumbres y en títulos. Por lo tanto, la organización del agua dada a partir de 1886 no puede ser considerada como una continuidad del pasado; aunque ello significara igualmente una fuente de conflictos entre usuarios de aguas arriba y aguas abajo. De esta manera, el conflicto endémico provocado por la escasez del agua ha sido uno de los rasgos del sistema moderno de distribución de las aguas desde sus inicios.

El Reglamento para el Sindicato de Aguas de Cerrillos (1886) significó un cambio en la perspectiva del manejo del agua a nivel local. Su puesta en funcionamiento llevó a la consolidación del proceso de centralización del manejo del agua a cargo del Concejo. De allí que el Reglamento llevara a convalidar las costumbres y los títulos de propiedad de los grandes propietarios locales, quienes intervenían de manera simultánea en el Concejo Municipal y en el Sindicato de Aguas. Ello se advierte de los reglamentos de distribución de las aguas hacia el interior de los distritos donde se observa, por un lado, a los beneficiarios del uso del agua y, por el otro, el modo de cómo se distribuían las aguas. Por ejemplo, lo señalado anteriormente queda reflejado en la distribución del agua en las acequias de la Cañada 
y de San Agustín hacia 1887. Allí, el agua de las acequias solo beneficiaba a unos cuantos propietarios, dueños de las fincas más grandes del distrito: San Agustín, de la Cañada y el Bordo de San Agustín. El acceso a la misma se hacía mediante derecho al agua y de acuerdo a como estaban indicados en sus títulos. Esto estaba discriminado basándose en partes de agua, que eran medidas de acuerdo a un marco partidor o a una compuerta que, generalmente, servía para aforar el caudal de agua recibido ${ }^{30}$.

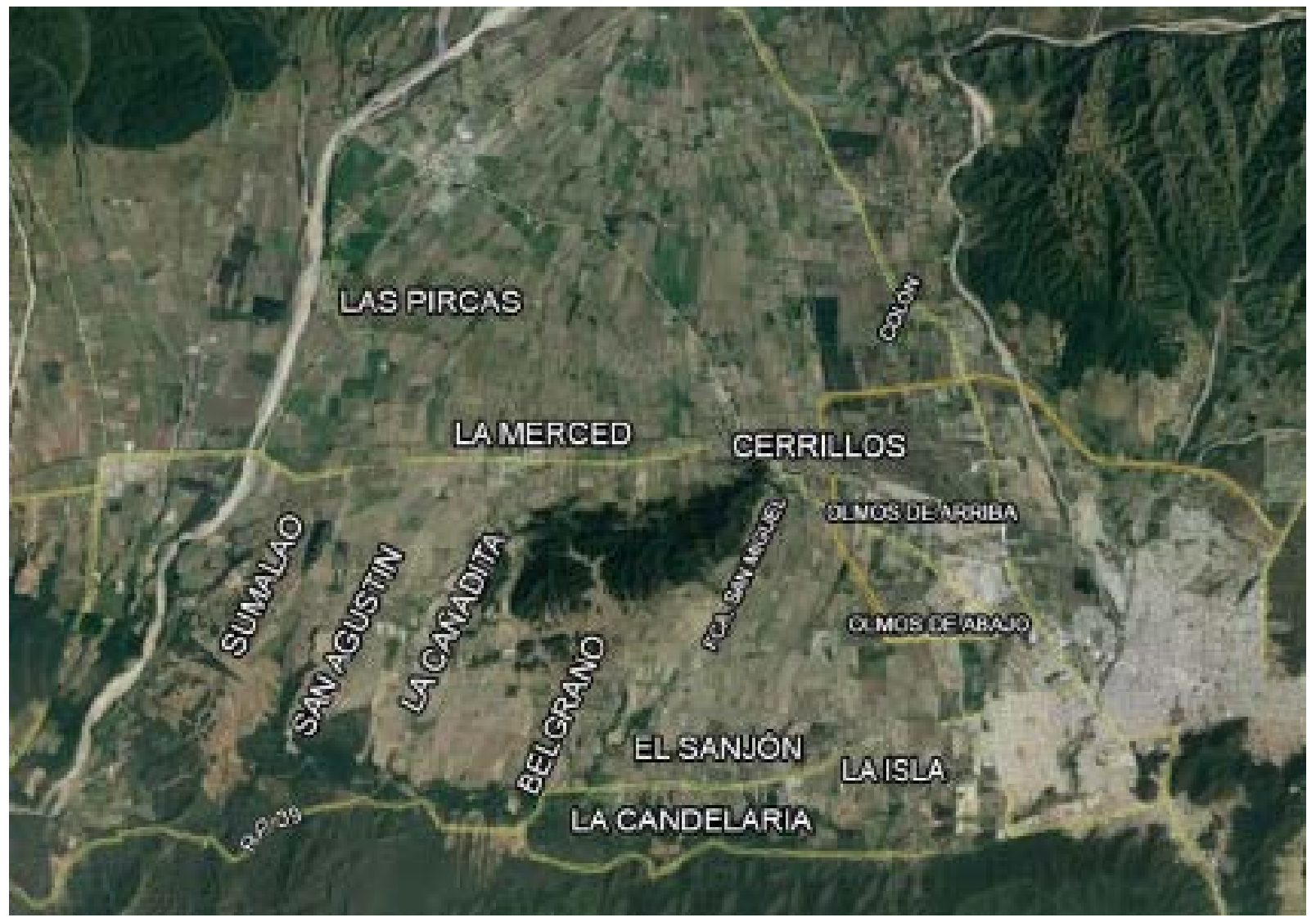

Mapa 2. Nombre de los distritos del Departamento de Cerrillos a fines del siglo XIX Fuente: Elaboración propia

30 AHMC, $A C M$, "Datos para la distribución del agua de las acequias de la Cañada y de San Agustín" 1887. 


\section{De la presión sobre los recursos (Tierra y Agua) y el vínculo con la política}

Es en el marco de los procesos de centralización administrativa llevadas a cabo por el Concejo Municipal de Cerrillos, y de las transformaciones económicas provocadas por el incremento de la frontera agraria, que se comenzará a observar un aumento notable de la participación de los grandes propietarios en la cuestión política local. A diferencia del período anterior, esto es aproximadamente hasta mediados de la década del '80. La participación en la política por parte de los grandes propietarios del departamento había sido escasa o, sin la notoriedad evidenciada desde ese período en adelante. Al parecer, fueron las nuevas condiciones de producción y de la presión sobre los factores de producción (Tierra ${ }^{31}$ y Agua), resultado del desarrollo del capitalismo agrario y del circuito ganadero en la región del Noroeste argentino, las que provocaron que la política se convirtiera en un andamiaje que les permitiera obtener ventajas en términos económicos y de defensa de sus propios intereses. Precisamente, fueron esos cambios dados a nivel regional los que impulsaron un mayor interés por la participación política. Ello significó, en pocas palabras, que el panorama político manifestado hasta el momento, comenzara a nutrirse de cambios en términos de una mayor participación en el Concejo Municipal, lugar donde se entrecruzaron los intereses y conflictos de grupo. Ello se ve reflejado en la participación que tuvieron los siguientes propietarios en el Concejo Municipal:

$31 \quad$ Existen diversos trabajos que nos indican sobre la presión ejercida sobre las tierras del Valle de Lerma y Calchaquí, por parte de integrantes de una burguesía terrateniente que lo hacía en virtud de una lógica de organización del espacio a escala provincial en torno al circuito ganadero. En ese esquema, como ya lo sabemos, tanto los valles de Lerma y Calchaquí se especializaron en la producción de Alfalfa. Así, nos lo demuestra Slavustky, quien aporta datos respecto a: “...como el sistema de propiedad de los Valles Calchaquies y Lerma se vinculan con la expansión hacia el este cuyo desarrollo consolida el poder de esta burguesía terrateniente y la sitúa como actora política de la organización nacional...". En esa lógica económica, el ganado que era criado en el Chaco, era engordado en los Valles de Lerma y Calchaquíes y luego cruzaba la cordillera. Unos años antes, Michel y Savic ya habían llamado la atención sobre la existencia de un grupo terrateniente mercantil provincial cuyo objetivo fue el monopolio del negocio ganadero y el control de la política a través de la explotación de las redes familiares. Ellas señalan que eran las estancias y fincas las que predominaban en las transacciones y que demostraban un proceso de acaparamiento de tierras. Según su hipótesis de trabajo, ello había sido posible debido a su participación en los circuitos comerciales y por un calor dominio en la política. En el caso particular del Departamento de Cerrillos, si bien existen compra-venta de propiedades, ellas por si mismas no son suficientes para entender lo señalado por las autoras dado que son pocas en relación a la gran cantidad que se realiza en el Valle de Lerma y Calchaquí. Empero, el dato es válido si lo consideramos como evidencia de la especialización regional en torno al circuito ganadero y de la cual nuestro departamento forma parte. Esas transacciones se refieren a las adquisiciones de Don Félix Usandivaras de las fincas Santa Elena (1896) y San Agustín (1912) de Ricardo Isasmendi (o Isasmedi y Compañía) de una finca en el Zanjón (1909). Léase a: Michel y Savic, "Comerciantes-ganaderos y propietarios. Salta (1880-1920)"..., 19; Ariel Slavustky, "La organización del espacio y conformación de la Burguesía salteña," (Ponencia presentada en XI Jornadas Interescuelas/Departamentos de Historia. Tucumán: Departamento de Historia. Facultad de Filosofía y Letras, 2007). 
Listado de propietarios notables del Departamento de Cerrillos (ordenados alfabéticamente), $1894^{32}$.

- Dr. Rudecindo Aranda (ya fallecido)

- Don Miguel Boedo

- Don Pedro H. Cánepa

- Don Benjamín Dávalos

- Don Manuel Peña

- Don Gustavo Marrupe

- Don Ysauro Ruiz
- Don Pedro Arias

- Don Nicolás Arias Cornejo

- Don Belisario Dávalos

- Don Alejandro Figueroa

- Don Pedro Y. López,

- Don Juan Reimundín

- Don José Zorrilla

De la confluencia de datos provenientes de las Actas del Concejo Municipal (de donde se han podido reconstruir algunas series continuas de la composición del mismo) y de un Informe del año 1894, arribamos a una interesante conclusión: la mayoría de los propietarios mencionados en este, estuvieron formando parte del Concejo Municipal (ver cuadro) y de los Sindicatos de Aguas. Recordemos que las razones de este hecho, notable por cierto, se debe a: 1) cambios en el sector de la producción agrícola, asociados a la complementariedad ganadería-agricultura y riego; 2) al desarrollo de una lógica de organización del espacio a escala provincial en torno al circuito ganadero; 3) a una mayor presión sobre los factores de producción (Tierra y Agua) por parte de propietarios locales y foráneos, en virtud de su intervención en órganos políticos a favor de lograr beneficios económicos; finalmente, 4) pretensión de los grandes propietarios de lograr una mayor participación en los procesos hegemónicos a nivel municipal.

Respecto a los propietarios considerados como dueños de las fincas de primer orden, observamos que dos de ellos participaron asiduamente en el Concejo entre 1886 a 1898. Uno de esos casos es el de Don Pedro Cánepa, quien lo hizo en 1886, 1887, 1888, 1893, 1894, 1895, 1896 y 1898. Otro es el de Don Nicolás Arias Cornejo, propietario de la finca la Cañada, en: 1886, 1890, 1891, 1892, 1893, 1894, 1895, 1896 y 1898. Otros propietarios de segundo orden, también estuvieron presentes en la composición del Concejo Municipal. Casos interesantes fueron: Don Belisario Dávalos, propietario de tierras en la Merced, con participaciones en los años 1886, 1887, 1888, 1889, 1890, 1891, 1892, 1893, 1894, 1895, 1896 y 1897; y Don Miguel Reimundín, dueño de un molino hidráulico en el distrito de Colón, quien participó en los años 1883, 1884, 1886, 1887, 1888, 1889, 1890, 1891, 1892 y 1893. Otros casos, fueron Don Pedro y López (1890 y 1892), Don Ysauro Ruiz $(1895,1897)$ y Don José Zorrilla (1894, 1895).

32 AHMC, $A C M$, "Informe que presenta la Municipalidad del Departamento de Cerrillos al Gobierno de la provincia conforme decreto de fecha el 25 de agosto de 1894" 1894. 
Como se advertirá, no todos se hallaron presentes en el Concejo Municipal, lo cual no significa que no hayan tenido participación en la política local. De entre ellos, hay que señalar a los que intervinieron en otras instancias de poder como los Juzgados de Paz en sus distritos de origen. Si bien existen varios propietarios que aparecen en la nómina como propietarios y suplentes, solo nombraremos a dos: Don Gustavo Marrupe, de quien tenemos el dato que estuvo en el Concejo en el año 1889, y como Juez de Paz de la Isla en 1892, 1893, 1894, 1897 y 1898. El otro, Don Nabor Boedo, lo hizo también como concejal (1883 y 1885). En carácter de Juez de Paz, los registros lo muestran junto con el Dr. Macedonio Aranda en varias oportunidades. En general, entre 1883 y 1898 se observa una notable intervención en la política de parte de algunos propietarios, muchos de ellos, sin lugar a dudas lo hicieron por un interés manifiesto por el agua. Ello, contribuye al entendimiento de la situación de conflictos de intereses que existe en este período en torno al tema hídrico.

Teniendo en cuenta la composición de los Sindicatos de Agua (departamental y mixto), observamos que varios de los propietarios citados anteriormente fueron activos participantes durante años. Es así que, hacia 1886, el Sindicato del Agua departamental -estructura jerárquica conformada a los efectos del manejo del agua a nivel departamental-, estuvo compuesto por los siguientes propietarios:

- Don Dalmacio Mera (propietario -Juez de Paz del departamento)

- Don Gaspar Solá (propietario)

- Don José Zorrilla (dueño de finca en la Cañada y productor de cal)

- Don Nabor Boedo (dueño de finca en la Merced)

- Don Waldo Villaroel (de participación activa en el Concejo en rangos inferiores)

- Don Miguel Boedo (dueño de finca en la Merced y dueño de hornos para quemar cal)

- Don Juan Reimundín (dueños de tierras en Colón y de un molino hidráulico)

- Don Pablo Saracho (propietario).

Un año después, en 1887, frente a la conformación del Sindicato Mixto de Aguas en la que participaron los municipios de Cerrillos y Rosario de Lerma, el Concejo Municipal nombró como representantes departamentales a los siguientes propietarios: Don Belisario Dávalos, a Don Miguel Reimundín y a Don Navor Boedo. 


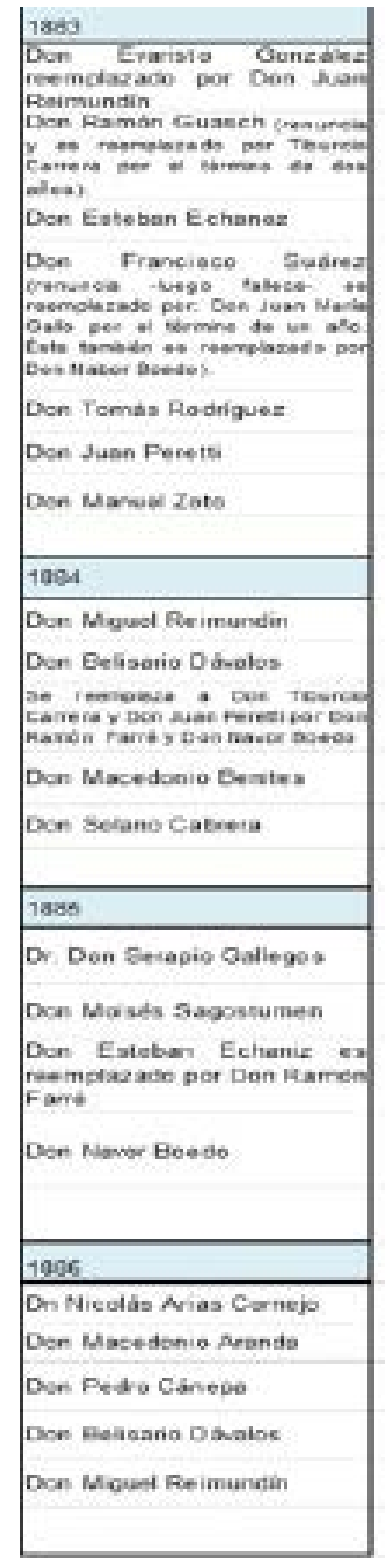

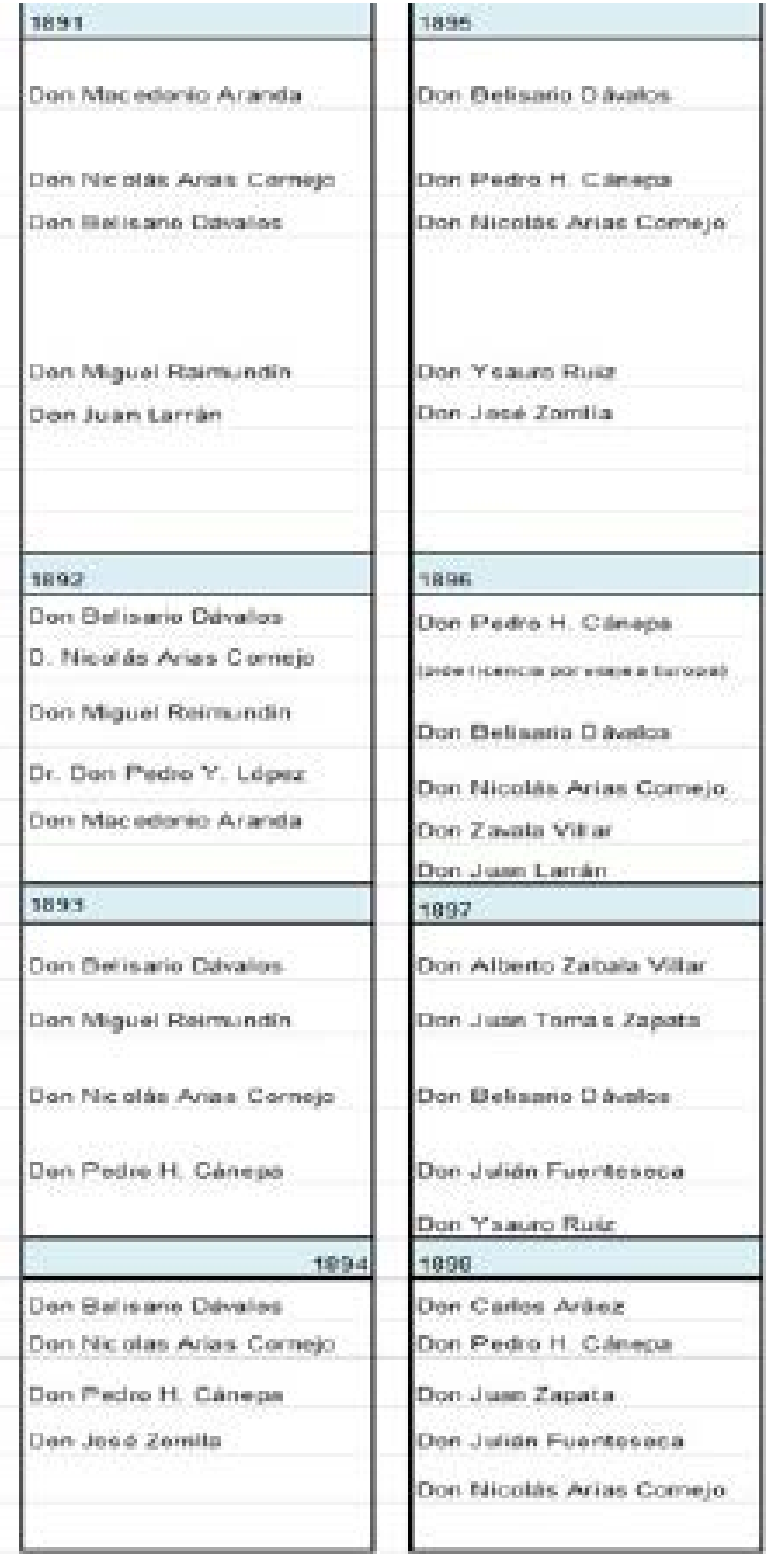

Cuadro 1. Participación de los propietarios en el Concejo Municipal (1883-1898) Fuente: AHMC, $A C M, 1883-1898$.

Como se podrá inferir, la participación de los dueños de la tierra, en un tema tan importante como el manejo y la distribución del agua, resultó ser imprescindible a los efectos de la defensa de sus intereses frente al incremento de la demanda del recurso. De los nombres citados, la mayoría lo hizo también en carácter de integrantes del Concejo Municipal: Don Belisario Dávalos, Don Miguel Reimundín, Don Navor 
Boedo y Don José Zorrilla. Esto confirma la idea del porqué de la participación activa en la toma de decisiones políticas a nivel local.

Unos años después, esto es entre 1891-1896 (momento en el que en la composición del Concejo se manifiesta una llamativa participación de algunos grandes propietarios), observamos que algunos de los propietarios citados en la página anterior, también aparecen participando en el Sindicato de Aguas departamental. Ellos fueron Don Pedro Cánepa, Don Juan Reimundín (hermano de Miguel quien interviene en el Concejo Municipal), Don Dalmacio Mera (propietario y Juez de Paz departamental en 1893), Don Belisario Barón, Don José Vázquez Freire (concejal en 1888 y 1887), Don José María Gallo (propietario y concejal en 1883), Don Daniel Carreras, Don Severo Campos (propietarios en el distrito de Olmos y de participación en el Concejo Municipal a principios del '80), Don Felipe Mendoza y Don Moisés Gutiérrez.

Un año después, cuando se designó a la Comisión Directiva del Sindicato, se advierte que su composición fue casi similar a la manifestada anteriormente. Si bien del listado no tenemos los nombres de los otros integrantes, salvo la parte ejecutiva, tanto Manuel Dondiz como Miguel Boedo fueron dignos representantes de los dueños de las tierras. Razón por la cual, la situación no cambió en relación a lo antedicho precedentemente.

\begin{tabular}{|ll|}
\hline NOMBRES Y APELLIDOS & CARGO \\
\hline Manuel Dondiz & Presidente \\
Miguel Boedo & Vice- presidente \\
Waldo Villaroel & Secretario- Tesorero \\
Francisco E. Echazú & Juez de Bocas Tomas \\
Francisco Avilés & $\begin{array}{l}\text { Comisario Repartidor entre los propietarios de } \\
\text { "Olmos" }\end{array}$ \\
Ciriano Vázquez & Juez Repartidor entre los propietarios de Colón \\
Antonio Jiménez & $\begin{array}{l}\text { Juez Repartidor entre los propietarios de la acequia } \\
\text { "Gallo" }\end{array}$ \\
Feliciano Medrano & $\begin{array}{l}\text { Juez Repartidor entre los propietarios de Arias y San } \\
\text { Agustín }\end{array}$ \\
\hline
\end{tabular}

Cuadro 2. Miembros del Sindicato de Aguas, 1896

Fuente: AHMC., Libro de Actas 1891-1897.

En este breve apartado, hemos encontrado suficientes pruebas para demostrar la participación de los propietarios en las esferas del poder. Asimismo, un incremento en sus intervenciones, tanto en el Concejo Municipal como en los Sindicatos de agua. Al respecto, no está de más sugerir hipótesis respecto a que dicha participación fue 
en respuesta a las transformaciones económicas dadas a nivel regional (reorientación productiva a favor de la agricultura, desarrollo de los circuitos hacia la ganadería exportada al norte chileno, complementariedad de propiedades a los efectos del circuito ganadero, etc.), lo cual motivó la necesidad de control de los factores de producción, tales como el agua para riego, a efectos de lograr mayores beneficios económicos; de allí los conflictos de intereses que se manifiestan durante este período de transformaciones.

\section{Consideraciones finales}

En el presente artículo hemos podido avanzar sobre el conocimiento respecto a los cambios dados en el Departamento de Cerrillos a finales del siglo XIX, en lo referido a la gestión y la administración del agua para riego. Basándonos en información de carácter cualitativo proveniente de la Ordenanza que dio forma al Sindicato de Aguas (creado el 31 de julio de 1886) y al Reglamento de Aguas (1887) creado por este, hemos constatado que el caso cerrillano, no se aleja de la situación planteada en otros espacios, como el caso mexicano, respecto al riego.

La vinculación directa entre la reglamentación y la conformación de una organización de regantes (Sindicatos), por un lado, respondió a una instancia gubernamental, planteada desde la legislación nacional y provincial y de la acción del gobierno local, en confluencia de las demandas e intereses de los propietarios de las tierras. Por otro, a las transformaciones agrarias dadas en el área de estudio, producto del desarrollo del capitalismo imperante en aquel entonces.

La reglamentación constituye una parte fundamental de los procesos de centralización administrativa llevadas a cabo por el Concejo Municipal cerrillano y el Ejecutivo provincial salteño en torno al manejo del agua. Al igual que en otras áreas agrícolas sometidas al desarrollo agrario capitalista, significó un cambio en la naturaleza organizativa sobre la gestión y administración del agua. Por lo tanto, los reglamentos son obras de instancias gubernamentales que fueron elaborados con el propósito de que fueran implementados a efectos de un orden ${ }^{33}$. A decir de Giménez y Palerm, que estudian las organizaciones tradicionales del agua en España, la intervención del Estado en la administración de los regadíos ha sido importante, lo que se hace evidente en la revisión y análisis de legislaciones ${ }^{34}$.

Lo estudiado demuestra que a fines del siglo XIX hubo un cambio legal fundamental en la gestión y administración del agua en el Departamento de Cerrillos, logrado mediante la erección de una nueva estructura de gestión manejada por un cuerpo

33 Palerm, "Las Juntas de Agua y las Unidades de Riego".

34 María Giménez Casalduero y Jacinta Palerm Viqueira, "Organizaciones tradicionales de gestión del agua: importancia de su reconocimiento legal para su pervivencia. El caso de España," Región y Sociedad 38. 19 (2007): 5. 
de funcionarios abocados directamente al manejo del agua. En este sentido, está claro que no hubo una continuidad respecto a formas organizativas anteriores, sino que, fue reemplazada por una organización (Sindicato de Aguas) surgida por mandato del Estado. Ello, sin embargo, no invalida las posibilidades que surgieran manifestaciones de resistencia, por parte de los regantes, frente a los intentos de imposición de nuevo orden hídrico de parte del Estado. El análisis del Reglamento pone de manifiesto la necesidad que había en aquel período de regular el manejo del agua, intentando terminar con ello, los conflictos y las tensiones que habían surgido alrededor de su uso para riego, y que fuera producto del impacto del desarrollo del capitalismo agrario.

A partir de la observación de otras áreas de estudio ${ }^{35}$, se constata que la conformación de los órganos corporativos bajo mandato del Estado (Juntas de Aguas, Sindicatos, etc.) y los reglamentos del agua inician un capítulo importante en el intento de centralizar la gestión y distribución de las aguas dado que, representó un punto de inflexión muy importante en lo referido al tema de la institucionalización del manejo del agua. En ese sentido, es evidente que con la creación del Sindicato y el Reglamento de Aguas del Departamento de Cerrillos a fines del siglo XIX, tal cual sucedió en barranca Amatzinac (México) ${ }^{36}$, se generó un mecanismo integrador y cohesionador de los regantes, cambiando la lógica de gestión y administración del riego dado hasta ese momento.

Para concluir, hemos constatado la vinculación que existió entre la evolución del manejo hídrico -reflejada a través de los Reglamentos de agua y creación de los Sindicatos-, con las estructuras de poder, y con aquellos procesos de centralización y estatización llevados a cabo por el Concejo Municipal cerrillano. Los intentos llevados a cabo por el estado local han sido resultado de una demanda creciente por parte de los propietarios de la tierra sobre la reglamentación, el manejo y la distribución de las aguas. Fue en esta entidad administrativa, en la que se concentraron integrantes de una élite local, donde se gestó una serie de acciones legislativas tendientes a una mayor centralización del manejo del agua. El hecho de que el Concejo Municipal fuera el promotor de un ordenamiento jurídico y burocrático se explica por la intervención, en su seno, de sectores de la sociedad (minoría propietaria) que influyeron a favor de la normativización de las prácticas sociales relacionadas con el agua. De esa manera, la legislación en Cerrillos fue el basamento jurídico que contribuyó al control de las aguas de parte de una élite dirigente dominante, dueña del factor tierra y monopolizadora de los resortes del poder político.

35 Palacios, "Sobre las Juntas de Aguas," 217-225; Laura R. Valladares de la Cruz, "Conflictos hidráulicos en Morelos 1880-1940: de era de la hacienda al modelo ejidal campesino," Boletín Histórico del Agua: Organizaciones autogestivas para el riego, Nueva época 9 (2004).

36 María Rivas Guevara, "Organización y readaptación organizativa para el riego: barranca Amatzinac, zona baja y Canal Tenango, Morelo," Boletín Histórico del Agua: Organizaciones auto-gestivas para el riego, Nueva época 9, (2004): 80-84. 


\title{
Bibliografía
}

\section{1. $\quad$ Fuentes primarias ${ }^{37}$}

A. Archivos

\section{Archivo Histórico Municipal de Cerrillos, Cerillos, Argentina (AHMC)}

\author{
Actas del Concejo Municipal (ACM)
}

\section{Fuentes secundarias}

Ashur, Eduardo. "Introducción". en La crisis del agua en Salta. Entre la sequía y la inundación. Editado por Terry Hoops y Eduardo Ashur. Salta: Center for latin American and Caribean Studies- Universidad Estatal de Michigan- Fundación CAPACITAR, 2004.

Ashur Mas, Diego. "Salta: La institucionalización del agua". en La crisis del agua en Salta. Entre la sequía y la inundación. Editado por Terry Hoops y Eduardo Ashur. Salta: Center for latin American and Caribean Studies- Universidad Estatal de Michigan- Fundación CAPACITAR, 2004.

Ávila García, Patricia. "Cambio global y recursos hídricos en México: hidropolítica y conflictos contemporáneos por el agua". en Instituto Nacional de Ecología (2004).

Cornejo Atilio. Contribución a la Historia del Derecho de Aguas de Salta. Salta: Publicación del Instituto de San Felipe y Santiago de Estudios Históricos de Salta, 1980.

Giménez Casalduero, María y Palerm Viqueira, Jacinta. "Organizaciones tradicionales de gestión del agua: importancia de su reconocimiento legal para su pervivencia. El caso de España”. Región y Sociedad 38.19 (2007): 3-24.

37 Las fuentes primarias utilizadas en esta investigación poseen un gran valor documental, dado que registra la dinámica política del Concejo Municipal, a través de las Actas de Sesión desde donde se pueden inferir conflictos e intereses de grupo. 
Gómez Serrano, Jesús. "La administración de agua en el tránsito del Antigua Régimen a la República. Aguascalientes, 1821-1835”. Relaciones 136 (2013): 187-222.

Michel, Azucena del Valle y Savic, Elizabeth. "Comerciantes-ganaderos y propietarios. Salta (1880-1920)". Cuadernos de Humanidades 11 (1999): 179-210. Salta, Universidad Nacional de Salta, Facultad de Humanidades.

Miranda, Omar. "Trayectoria tecnológica y uso del agua en la Agricultura argentina bajo riego". Revista Agricultura, Sociedad y Desarrollo 6.5 (2009).

Ontivero, Daniel Medardo. Riego, Poder y Estado municipal en San José de los Cerrillos (Salta 1857-1920): entre tensiones, conflictos y procesos de modernización. Tesis doctoral (Inédita). Universidad Nacional de Tucumán (UNT); Facultad de Filosofía y Letras, 2018.

__. "Efectos del desarrollo salitrero en el noroeste argentino. El caso de San José de los Cerrillos a fines del siglo XIX". Revista Notas Históricas y Geográficas, 20 (2018): 88-121.

Rivas Guevara, María. “Organización y readaptación organizativa para el riego: barranca Amatzinac, zona baja y Canal Tenango, Morelo". Boletín Histórico del Agua: Organizaciones auto-gestivas para el riego, Nueva época, año 9, (2004): 80-84.

Palerm, Jacinta. "Las Juntas de Agua y las Unidades de Riego. en Aventuras con el Agua. La Administración del agua de riego: Historia y Teoría. Editado por Jacinta Palerm Viqueira y Tomás Martínez S. México: Colegio de Postgraduados, Sede Montecillo en Texcoco, 2009.

Palerm Viqueira, Jacinta y Martínez S., Tomás, Eds. Aventuras con el Agua. La Administración del agua de riego: Historia y Teoría. México: Colegio de Post- grado, Sede Montecillo en Texcoco, 2009.

- "El espíritu colectivo en los sistemas de riego", en Aventuras con el Agua. La Administración del agua de riego: Historia y Teoría. México: Colegio de Postgraduados, Sede Montecillo en Texcoco, 2009. 
Palerm Viqueira, Jacinta y Martínez Saldaña, Tomás. Antropología del Agua. Mimeo, $(\mathrm{s} / \mathrm{f})$.

Palacios Vélez, Enrique "Sobre las Juntas de Aguas". en Aventuras con el Agua. La Administración del agua de riego: Historia y Teoría. Editado por Jacinta Palerm Viqueira y Tomás Martínez S. México: Colegio de Postgraduados, Sede Montecillo en Texcoco, 2009.

Rodríguez L., Antonio. "El desarrollo y operación de los sistemas de riego en México". en Aventuras con el Agua. La Administración del agua de riego: Historia y Teoría. Editado por Jacinta Palerm Viqueira y Tomás Martínez S. México: Colegio de Post- grado, Sede Montecillo en Texcoco, 2009).

Slavustky, Ariel. "La organización del espacio y conformación de la Burguesía salteña". Ponencia presentada en XI Jornadas Interescuelas/Departamentos de Historia. (Tucumán: Departamento de Historia. Facultad de Filosofía y Letras, 2007).

Valladares de la Cruz, Laura R. "Conflictos hidráulicos en Morelos 1880-1940: de era de la hacienda al modelo ejidal campesino". Boletín Histórico del Agua: Organizaciones autogestivas para el riego, Nueva época, año 9, (2004).

Villareal, Federico y Manzanal, Mabel. "Descentralización y poder en la administración del agua de riego. El caso de la cuenca del río Calchaquí en el departamento de San Carlos, Salta, Argentina". Campo Territorio: Revista de geografía agraria, $\mathrm{n}^{\mathrm{o}} 12$ (6), (2011): 32-62. 